\title{
Increasing Article Visibility: JABFM and Author Responsibilities and Possibilities
}

\author{
Anne Victoria Neale, PhD, MPH, Phil Lupo, MLIS, Marjorie A. Bowman, MD, MPA, \\ and Dean A. Seebusen, MD, MPH
}

\begin{abstract}
JABFM seeks to widely disseminate its peer-reviewed publications, increasing article visibility for the purpose of advancing scientific knowledge. We describe the journal's approach to dissemination and recommend a number of strategies for authors to implement, including press releases and social media. Providing the article's digital object identifier (DOI) is most useful, compared with links that can break, or attaching the article PDF, which will depress reader metrics. All JABFM articles are freely accessible online worldwide. (J Am Board Fam Med 2020;33:168-169.)
\end{abstract}

FABFM editors and editorial board members encourage a wide dissemination of all articles. Ensuring that scientific research is widely read is important to many stakeholders. For authors, their articles must reach end users to advance knowledge or change clinical practice. From the perspective of editors, readership increases the importance of the journal and can lead to citations. Article citations drive journal impact factors but reflect only 1 facet of an article's impact. ${ }^{1}$ Citations take years to accrue and do not reveal reader interest or impact on practitioners engaged in translating research into practice; this is particularly true for clinical research, which is cited less frequently than basic science research, ${ }^{2,3}$ and yet may be influential to practitioners. Increasing article visibility and reader awareness may also be important to academic scholars, who can use a variety of alternative reader metrics to document reader interest in their work. ${ }^{1}$

Authors and the $7 A B F M$ collaborate to promote article visibility and readership. The proliferation of social media provides opportunities to increase the visibility of publications beyond the $7 A B F M$ 's traditional print and electronic publication formats. By using a multipronged approach to dissemination, authors can increase awareness of their articles by making them more visible through a reverberating web of social media.

Conflict of interest: The authors are editors of the $7 A B F M$.

Corresponding author: Phil Lupo, MLIS, Wayne State University, Detroit, MI 48201 (E-mail: jabfm@med.wayne. edu).

\section{Digital Object Number (DOI) versus URL (Uniform Resource Locator)}

DOI is the recommended approach to disseminate your work. Most importantly, DOIs are forever and will not result in broken links that may occur with URLs that are often temporary, especially if the hosting site changes. However, whether you use the DOI or the URL to the HTML version on the journal website, when readers click on a link, this provides a metric of use called "readership," and this evidence of use may be useful for author efforts to document the impact of their work, such as in a promotion application. It is also useful for editorial boards to understand the extent to which each article is read.

\section{Author Responsibilities}

Authors have a major role in promoting visibility and readership of their work. Authors will benefit from publicizing their work and linking their publication to social media. Keep in mind (as discussed above) that disseminating the PDF will depress readership metric; it is preferable to disseminate the article's unique DOI. So, in each of the following, include a link to the DOI or HTML full-text on the $7 A B F M$ home page. Avoid attaching the article PDF, as readership numbers are not captured from PDFs, only from links.

1. Press Releases: Develop press releases with your institution's office of marketing and communications. Strategize about dissemination outlets with your institution.

2. Social Media: Condense press releases to develop a brief synopsis for social media. Assist 
readers to find your article by including the article DOI, which may be shorter than the URL.

- Include a synopsis and link to your article on social media sites (e.g. LinkedIn and Doximity).

- Tweet and post about accepted or newly published papers.

- Email links to your article to colleagues and interested others.

3. Open Researcher and Contributor ID (ORCID): Add article details to your ORCID profile. The ORCID is a nonproprietary alphanumeric code to uniquely identify scientific and other academic authors and contributors. Visit https://orcid.org/ for more information.

4. Google Scholar: An online, freely accessible search engine that lets users look for both physical and digital copies of articles. If your publication is not found in Google Scholar, you can manually add your article. Go to http://posts.google.com/author.

\section{JABFM Actions to Promote Article Visibility}

FABFM actively promotes the visibility of your article in the following ways:

- Open Access: The free, immediate, online availability of research articles coupled with the rights to use these articles fully in the digital environment (SPARC). ${ }^{4}$ Open access articles have higher citations compared with subscription access articles. ${ }^{5}$ Believing that the public and scientific communities are best served by open access to information, the American Board of Family Medicine provides $7 A B F M$ articles available free of charge and without registration at www.jabfm.org.

- eTOCS: Links to the HTML full-text articles are included in the table of contents (e'TOCs) for upcoming issues emailed to $7 A B F M$ subscribers $(>88,000)$. To become a subscriber, please go to: https://www.jabfm.org/alerts.

- Twitter: We tweet on articles "in press" or recently published. These have links to the "abstracts in press" page on the $7 A B F M$ website. See https://twitter.com/journal_board.

- Facebook: The editorial office links each new issue to our Facebook page (along with calls for papers and other important news): https://www. facebook.com/Journal-of-the-American-Board-ofFamily-Medicine-JABFM-40952212923/.
- YouTube: The 7ABFM YouTube channel is available for videos related to author publications and supplementary files. Contact the editorial office for more information (jabfm@med.wayne.edu) or the website https://www.youtube.com/channel/ UCy3WMU2yr5SD9zwoLJgqrsw.

- PubMed Central: The 7ABFM assists authors with meeting their obligation to deposit articles into PubMed Central. This satisfies the federal policy that NIH-funded research reports are made available to the public within 12 months of publication.

- Indexing: $7 A B F M$ content is indexed by Journal Citation Reports, Medline, MedScape, ProQuest, PubMed, Science Open, Web of Science, WONCA, and many other services. To see the full list, visit the $7 A B F M$ website at: (https:// www.jabfm.org/content/indexing).

- Editors' Blog: A summary of each issue is found on the "JABFM Editors' Blog", located on our website at: https://www.jabfm.org/content/editorsblog.

In summary, the $7 A B F M$ collaborates with authors to increase the impact of their work by using social media to reach policymakers and clinical care providers. The ultimate goal is to hasten primary care research into practice. We welcome reader suggestions for additional strategies to improve the visibility of author publications (e-mail: jabfm@med. wayne.edu).

To see this article online, please go to: http://jabfm.org/content/33/ 2/168.full.

\section{References}

1. Akers KG. Introducing altmetrics to the Journal of the Medical Library Association. J Med Libr Assoc 2017;105:3

2. Opthof T. Differences in citation frequency of clinical and basic science papers in cardiovascular research. Med Biol Eng Comput 2011;49:613.

3. Van Eck NJ, Waltman L, van Rann AFJ, Klautz RJM, Peul WC. Citation analysis may severely underestimate the impact of clinical research as compared to basic research. PLoS One 2013;8: e62395.

4. Scholarly Publishing and Academic Resources Coalition (SPARC). Open Access. https://sparcopen. org/open-access/. Published November 14, 2019.

5. Patel RB, Vaduganathan $M$, Mosarla RC, Venkateswaran RV, Bhatt DL, Bonow RO. Open access publishing and subsequent citations among articles in major cardiovascular journals. The American Journal of Medicine 2019;132:1103-1105. 